\title{
Les poblacions de Silaum silaus (Umbelliferae) a Catalunya: distribució, ecologia, amenaces i estatus
}

\section{Moisès Guardiola}

C/ Sant Pelegrí, 11. 08301 Mataró

mogubu@telefonica.net

\section{Xavier Oliver}

Delegació de la Garrotxa de la Institució Catalana d'Història Natural

C/ de Fontanella, 3. 17800 Olot

xevioliver@terra.es

\section{Joan Font García}

Universitat de Girona. Grup de Recerca de Flora i Vegetació

Departament de Ciències Ambientals

Campus de Montilivi, 17071 Girona

fontgarcia.joan@gmail.com

\section{Resum}

S'aporten dades sobre les poblacions de Silaum silaus que actualment es coneixen a Catalunya, la majoria descobertes els últims anys. Es dimensionen les poblacions de cadascuna de les localitats, així com la seva distribució, hàbitat, fenologia, densitat per hàbitat, amenaces i impactes. Finalment es fa una anàlisi de l'estat de conservació de la població catalana segons els criteris UICN i propostes de conservació.

Paraules clau: Silaum silaus; població; hàbitat; conservació; flora amenaçada; Catalunya.

\begin{abstract}
The populations of Silaum silaus (Umbelliferae) in Catalonia: Distribution, ecology, threats and status

We report data of known Silaum silaus populations in Catalonia, most of which have been discovered recently. For each population we estimated the magnitude of individuals, their geographical range, habitat type, phenology, density, threats and impacts. Finally, we analyzed the conservation status of Silaum silaus in Catalonia with IUCN criteria and suggest some proposals for the conservation of the species.
\end{abstract}

Keywords: Silaum silaus; population; habitat; conservation; threatened flora; Catalonia. 


\section{Introducció}

Silaum silaus (L.) Schinz \& Thell. (Fig. 1) és una planta de la família de les umbel-líferes (= apiàcies) amb una distribució euroasiàtica, que s'estén des de la península Ibèrica al sud-oest, fins al sud de Suècia pel nord, i els Urals i l'Altai cap a l'est. Val a dir que a Suècia podria ser un arqueòfit o, fins i tot, un neòfit, ja que en algunes regions va ser introduïda amb material provinent d'Alemanya durant la Segona Guerra Mundial (Fröberg, 2009). També s'ha indicat, accidental, de la província de Jiangsu, situada a la costa oriental de la República Popular de la Xina (eFloras, 2013).

A la península Ibèrica és rara, i es coneix del terç nord, concretament a les províncies de Lleó (Gómiz, 2003), Santander, Guipúscoa, Segòvia, Navarra, Sòria, Àlaba, Osca, Saragossa i Girona (Gómez, 2003). Al vessant nord dels Pirineus sembla que seria present a tots els departaments francesos (Tela Botanica, 2013), tot i que només existeixen citacions concretes dels voltants de Perpinyà (DH 82, DH 91, DH 92; SILENE, 2013).

Bolòs \& Vigo (1990) i Bolòs et al. (2005) la consideren raríssima a Catalunya. La primera referència que es té de la presència de $S$. silaus al Principat prové d'Antoni de Bolòs (Bolòs, 1949), qui l'indica del Pla de la Pinya (Vall d'en Bas), prop d'Olot, a partir d'un plec de l'herbari Vayreda (BC596045, leg. E. Vayreda, IX-1890, ut Silaus pratensis), tot indicant que no havia estat inclosa a la Flora de

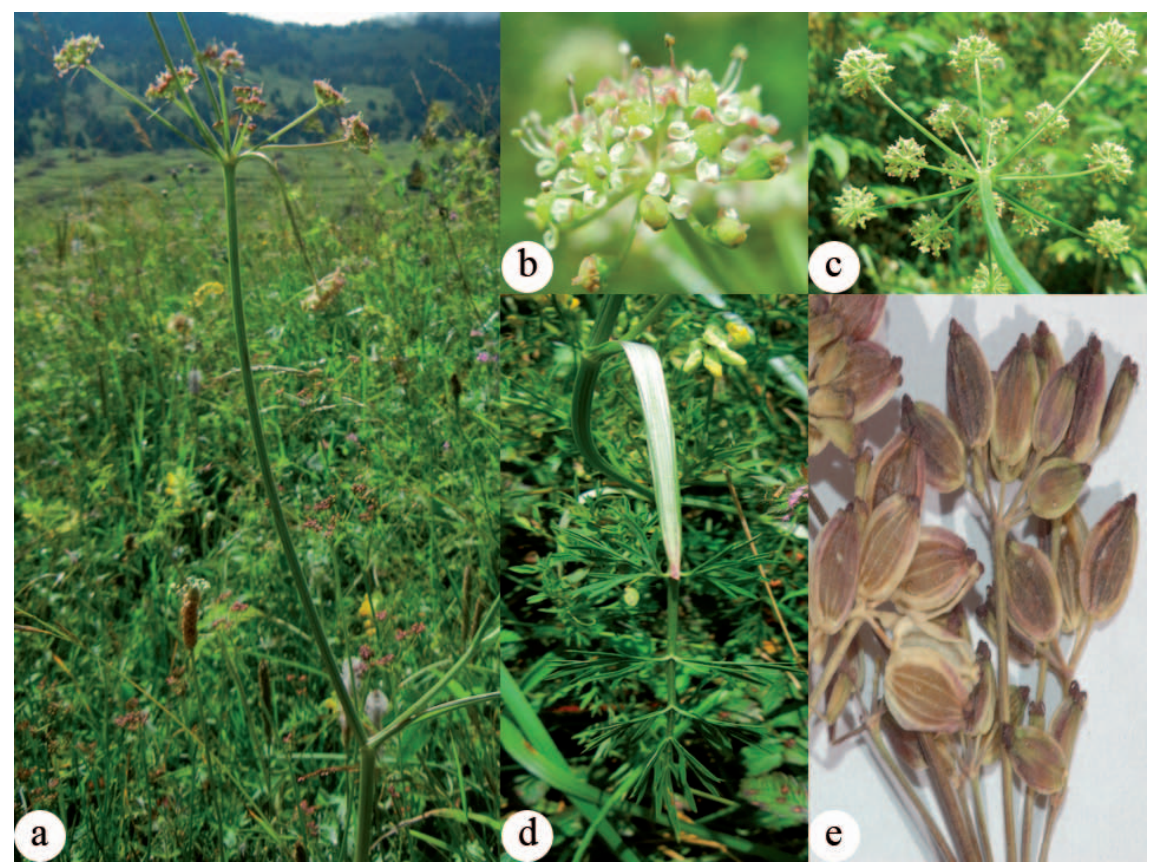

Figura 1. Aspecte de Silaum silaus: a) aspecte general, b) umbèl·lula, c) umbel·la, d) fulla, e) fruit. 
Catalunya de Cadevall (1913-1937). En aquesta localitat, però, mai hi ha estat retrobada (Oliver, 2008, 2012). A Catalunya no es torna a trobar aquesta planta fins que a l'any 1996 Josep Vigo en descobrí una altra població al Ripollès, concretament a Sant Antoni de Camprodon (J. Vigo, BCN 5396, in Bolòs et al. 1999).

Amb les dades que existien en aquell moment, Sáez et al. (2010) la van incloure en la categoria de vulnerable (VU C1 + 2a(ii); D2) segons criteris UICN (2001). L'espècie és inclosa a l' «Annex II» (espècies catalogades com a «vulnerables») del Decret 172/2008, de 26 d'agost, de creació del Catàleg de flora amenaçada de Catalunya de la Generalitat de Catalunya.

L'ecologia que se li atribueix és la d'aiguamolls, dins l'aliança Molinietalia (Bolòs \& Vigo, 1990; Bolòs et al., 2005), i prats higròfils, jonqueres, canyissars i clarianes forestals (Sáez et al., 2010).

En aquest treball presentem les dades d'unes prospeccions recents a les localitats conegudes i dades de noves poblacions que amplien significativament l'àrea de distribució coneguda a Catalunya, i que ajuden a delimitar el coneixement sobre la distribució, l'ecologia, les amenaces i l'estatus de S. silaus a Catalunya.

\section{Material i mètodes}

Des de l'any 2005, dins del Programa de seguiment i conservació de flora amenaçada a les comarques de la Garrotxa i del Ripollès, desenvolupat per la delegació de la Garrotxa de la Institució Catalana d'Història Natural, s'han prospectat les localitats on la planta havia estat citada fins al moment i també zones properes amb hàbitats idonis per a $S$. silaus. En totes les localitats on s'ha trobat la planta s'han realitzat censos i/o mostreigs de parcel-les per a determinar la dimensió de la població, les densitats, els hàbitats més propicis i concretar el seu estat de conservació. També s'ha cartografiat, sobre ortofotografies a escala 1:2.500 de l'Institut Cartogràfic de Catalunya (www.icc.cat), la distribució de cada població, i també s'han cartografiat aquelles zones prospectades on, malgrat haver-hi hàbitat idoni, no s'ha trobat $S$. silaus.

De cadascuna de les poblacions trobades, s'ha fet un cens directe de tots els individus en el cas de les poblacions amb menys de 5.000 individus, mentre que de les poblacions amb més efectius, tal com recomana Iriondo (2011), n'hem fet un cens indirecte per estimació. En aquest darrer cas, primer s'ha determinat el percentatge d'hàbitat idoni (diferents hàbitats favorables per a $S$. silaus) dins de les àrees cartografiades amb presència del tàxon, i després s'ha calculat la densitat d'individus en cada tipologia d'hàbitat idoni a partir de la mitjana de la densitat de la planta en els sectors amb hàbitat idoni. Finalment, per a cada tipologia d'hàbitat, s'ha calculat el nombre d'exemplars de cada població multiplicant el percentatge d'hàbitat idoni per la densitat d'individus en hàbitat idoni.

En totes les poblacions, a més de les dades de densitat puntual i global, i de l'hàbitat en què apareixia, també s'ha registrat la fenologia, els impactes i les amenaces detectades. I en les poblacions amb més diversitat d'hàbitats (poblacions 2, 3 i 5) s'han aixecat inventaris fitosociològics per caracteritzar els hàbitats on apareix $S$. silaus. 
L'avaluació del conjunt de les poblacions de S. silaus a Catalunya s'ha fet aplicant els criteris d'UICN a escala regional (UICN, 2003; Bubb et al., 2009). Per a la nomenclatura dels tàxons seguim Bolòs et al. (2005).

\section{Resultats i discussió}

\section{Poblacions catalanes}

Actualment es coneixen sis localitats amb poblacions de S. silaus a Catalunya, totes a la comarca del Ripollès (Fig. 2, Taula 1).

La població indicada al Pla de la Pinya a la Garrotxa (població 1) per E. Vayreda (Bolòs, 1949) no ha estat retrobada modernament, malgrat haver-la buscat intensament entre els anys 2004 i 2011, motiu pel qual es considera extingida (Oliver, 2008, 2012; Sáez et al., 2010). En aquesta localitat, S. silaus deuria créixer en prats higròfils i de dall, així com en herbassars higròfils de recs, basses $\mathrm{i}$ vorades de bosc, entre 450 i 550 m. Possiblement, les concentracions parcel-làries realitzades a la zona en les dècades dels anys quaranta i cinquanta del segle Xx, van dessecar la majoria de les zones humides del pla de la Pinya i, per tant, van eliminar o degradar els hàbitats idonis on podia viure la planta.

L'any 2005 es va retrobar (J. Font i X. Oliver) la població de S. silaus de Sant Antoni de Camprodon (població 2), trobada l'any 1996 per J. Vigo, i s'hi van

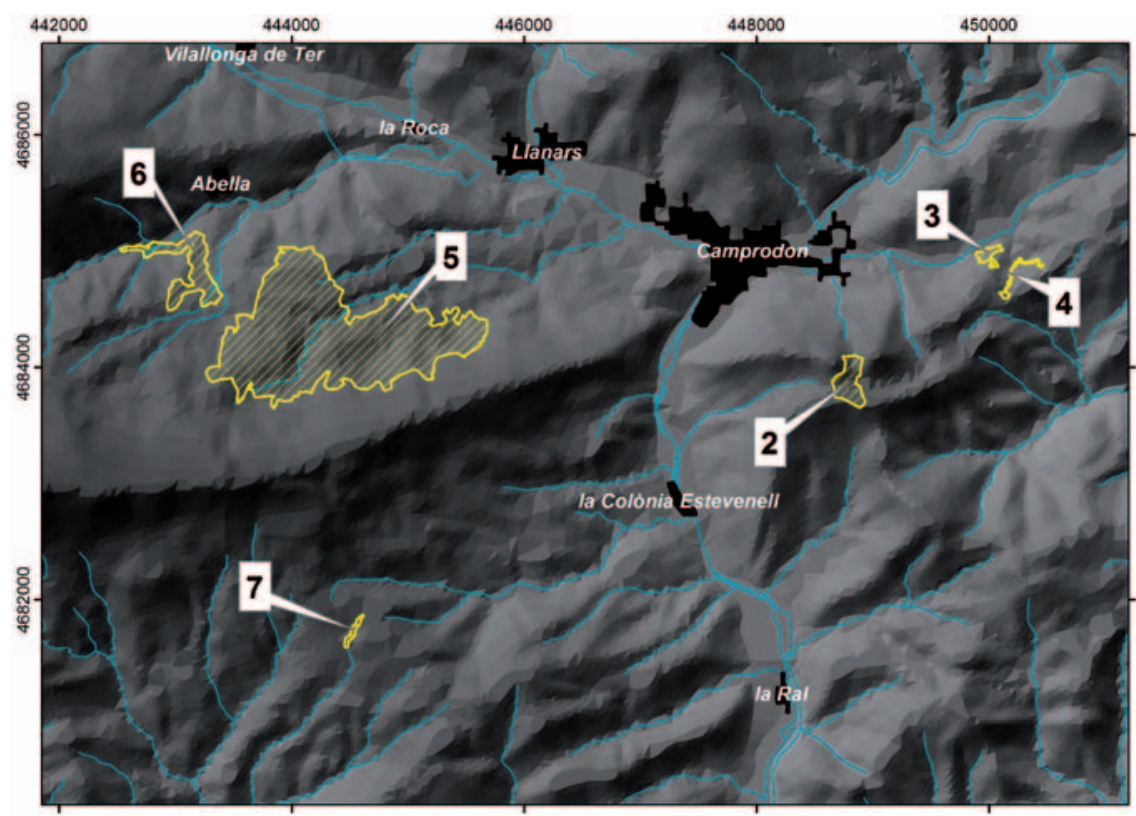

Figura 2. Distribució de les poblacions conegudes a Catalunya de Silaum silaus (polígons grocs). 
Taula 1. Característiques de les set poblacions de Silaum silaus citades a Catalunya. s.d. = sense dades

\begin{tabular}{|c|c|c|c|c|c|c|}
\hline Poblacions & $\begin{array}{c}\text { Municipi } \\
\text { (comarca) }\end{array}$ & $\begin{array}{c}\text { Autor } \\
\text { (any) }\end{array}$ & $\begin{array}{l}\text { Superfície } \\
\text { del rodal } \\
\text { amb el } \\
\text { tàxon (ha) }\end{array}$ & $\begin{array}{l}\text { Quadrats } \\
\text { UTM d'1 × } \\
\mathbf{1} \text { km }\end{array}$ & $\begin{array}{c}\begin{array}{c}\text { Població } \\
\text { (nre. }\end{array} \\
\text { d'exemplars) }\end{array}$ & $\begin{array}{c}\text { Densitat } \\
\text { mitjana } \\
\text { ind./m² }\end{array}$ \\
\hline $\begin{array}{l}\text { Pla de } \\
\text { la Pinya } \\
\text { (Localitat 1) }\end{array}$ & $\begin{array}{l}\text { Vall } \\
\text { d'en Bas } \\
\text { (Garrotxa) }\end{array}$ & $\begin{array}{l}\text { A. Bolòs } \\
\text { [Vayreda] } \\
(1949)\end{array}$ & s.d & s.d. & extingida & s.d. \\
\hline $\begin{array}{l}\text { Sant } \\
\text { Antoni de } \\
\text { Camprodon } \\
\text { (Localitat 2) }\end{array}$ & $\begin{array}{l}\text { Camprodon } \\
\text { (Ripollès) }\end{array}$ & $\begin{array}{l}\text { Vigo } \\
(1996)\end{array}$ & 7,65 & $\begin{array}{l}\text { DG } 4883 \\
\text { i } 4884\end{array}$ & 3.183 & 0,04 \\
\hline $\begin{array}{l}\text { El Ritortell } \\
\text { (Localitat 3) }\end{array}$ & $\begin{array}{l}\text { Camprodon } \\
\text { (Ripollès) }\end{array}$ & $\begin{array}{l}\text { Font \& } \\
\text { Oliver } \\
(2008)\end{array}$ & 1,86 & $\begin{array}{l}\text { DG } 4984, \\
5084 \text { i } 5085\end{array}$ & 602 & 0,4 \\
\hline $\begin{array}{l}\text { Coll de la } \\
\text { Creueta } \\
\text { (Localitat 4) }\end{array}$ & $\begin{array}{l}\text { Camprodon } \\
\text { (Ripollès) }\end{array}$ & $\begin{array}{l}\text { Font \& } \\
\text { Oliver } \\
(2008)\end{array}$ & 1,07 & DG 5084 & 106 & 0,1 \\
\hline $\begin{array}{l}\text { Serra } \\
\text { Cavallera } \\
\text { vessant nord } \\
\text { (Localitat 5) }\end{array}$ & $\begin{array}{l}\text { Vilallonga } \\
\text { del Ter i } \\
\text { Llanars } \\
\text { (Ripollès) }\end{array}$ & $\begin{array}{l}\text { Guardiola } \\
(2010)\end{array}$ & $9,8^{1}$ & $\begin{array}{l}\text { DG 4383, } \\
4384,4483, \\
4484,4583 \\
\text { i } 4584\end{array}$ & $4.800^{2}$ & 0.03 \\
\hline $\begin{array}{l}\text { Riera } \\
\text { d'Abella } \\
\text { (Localitat 6) }\end{array}$ & $\begin{array}{l}\text { Llanars } \\
\text { (Ripollès) }\end{array}$ & $\begin{array}{l}\text { Oliver } \\
(2011)\end{array}$ & $1,0^{1}$ & $\begin{array}{l}\text { DG } 4284, \\
4285,4384 \\
\text { i } 4385\end{array}$ & $500^{2}$ & 0.03 \\
\hline $\begin{array}{l}\text { Serra } \\
\text { Cavallera } \\
\text { vessant sud } \\
\text { (Localitat 7) }\end{array}$ & $\begin{array}{l}\text { Ogassa } \\
\text { (Ripollès) }\end{array}$ & $\begin{array}{l}\text { Guardiola } \\
\text { (2013) }\end{array}$ & 1,04 & DG 4481 & 100 & 0.09 \\
\hline TOTAL & & & 22,44 & $\begin{array}{l}16 \text { UTM } 1 \\
\times 1 \mathrm{~km}\end{array}$ & 9.291 & \\
\hline
\end{tabular}

${ }^{1}$ Superfície estimada amb presència del tàxon a partir del percentatge d'hàbitat idoni en les àrees cartografiades.

${ }^{2}$ Població estimada a partir de la superfície d'hàbitat idoni i la densitat per superfície d'hàbitat idoni.

cartografiar i censar 3.183 individus reproductors en 7,65 ha, distribuïts per prats pasturats (Cynosurion cristati), herbassars de vorada higròfils (Trifolion medii) i jonqueres acidòfiles (Juncion acutiflori) entre 1240 i 1320 m, en dos quadrats UTM d' $1 \times 1 \mathrm{~km}$ (DG 4883 i DG 4884), on tenien una densitat molt variable, de 0,04 ind. $/ \mathrm{m}^{2}$ de mitjana, però amb màxims de fins a 7 ind. $/ \mathrm{m}^{2}$.

L'any 2009 es van localitzar dues poblacions més al terme municipal de Camprodon (J. Font i X. Oliver), al Coll de la Creueta (població 3), i entre el Masot i el Ritortell (localitat 4), relativament properes a la població 2 (a uns $1400 \mathrm{~m}$ de distància en direcció nord-est), amb una superfície de 1,86 i 1,07 ha, i 602 i 106 
exemplars, distribuïts en prats humits (Cynosurion cristati) i herbassars higròfils de vorada (Trifolion medii) entre 1000 i $1050 \mathrm{~m}$, en quatre quadrats UTM $1 \times 1$ km (DG 4984, DG 4985, DG 5084 i DG 5085) i amb una densitat de 0,4 i 0,1 ind./ $\mathrm{m}^{2}$ respectivament.

L'any 2010 es va localitzar una nova població, molt extensa, al vessant nord de la Serra Cavallera (M. Guardiola), als municipis de Llanars i Vilallonga de Ter (població 5), en marges de prats de dall (Arrhenatherion elatioris) i altres prats higròfils (Cynosurion cristati), i herbassars higròfils de vorada (Trifolion medii). Aquesta població ocupa unes 163,64 ha, amb una superfície estimada d'hàbitat idoni de 9,8 ha, i una població estimada de 4.800 individus repartits en 6 quadrícules UTM d' $1 \times 1 \mathrm{~km}$ de costat (DG 4383, DG 4384, DG 4483, DG 4484, DG 4583 i DG 4584), des de 1140 m a 1420 m, entre les roques Gerdoneres, el turó del serrat dels Plans, el pla Rodó, el puig Ferriol, els Serbions i les Enderrocades.

L'any 2011 es va localitzar una altra població propera a l'anterior (X. Oliver), més al nord, dins del municipi de Vilallonga del Ter, al voltant de la riera d'Abella (població 6), d'unes 16,44 ha, amb una superfície estimada d'hàbitat idoni d'1 ha, i una població estimada de 500 exemplars, distribuïts en quatre quadrícules UTM d' $1 \times 1 \mathrm{~km}$ de costat (DG 4284, DG 4285, DG 4384 i DG 4385), entre els 1180 m i 1340 m, als voltants de can Ribera, can Gallina, la devesa del Rei i el cap del Serrat.

Aquestes dues darreres poblacions (poblacions 5 i 6) semblaven molt més grans i extenses que les anteriors, motiu pel qual no es va fer un cens directe del nombre d'individus, sinó que es va fer una estimació segons les densitats obtingudes per tipus d'hàbitat i de la superfície d'aquests en l'àrea d'ocupació de la localitat. El tàxon presentava densitats puntuals d'1-5 (màxim de 12) ind./m².

Finalment, afegim encara una altra població localitzada l'any 2013 a la solana de la Serra Cavallera (M. Guardiola), al Pla d'en Plata dins del municipi d'Ogassa (població 7), d'unes 1,04 ha i uns 100 exemplars, distribuïts en una única quadrícula UTM d' $1 \times 1 \mathrm{~km}$ de costat (DG 4481), entre els $1300 \mathrm{~m}$ i 1345 m, resseguint els marges dels cursos d'aigua i creixent a les jonqueres del Juncion acutiflori i els herbassars de vorada del Trifolion medii.

També volem deixar constància que en les prospeccions que es van realitzar l'any 2011 (X. Oliver i M. Guardiola) als prats de dall i herbassars higròfils de la meitat occidental de la Serra Cavallera a la vall de Ribes (municipi de Pardines) i als prats de dall de la Gironella (municipi de Camprodon) no es va detectar cap població de $S$. silaus. No descartem, però, que puguin trobar-se noves poblacions en algun sector proper de les poblacions conegudes, tot i que creiem que seran de pocs efectius poblacionals.

\section{Fenologia}

Silaum silaus és un hemicriptòfit que viu diversos anys. El cicle fenològic s’inicia cap al mes d'abril (Taula 2), quan comencen a brotar les gemmes persistents situades al coll de l'arrel. Floreix de juliol a novembre, amb un màxim de floració entre la segona quinzena d'agost i la segona quinzena de setembre. Fructifica 
Taula 2. Cicle fenològic anual de Silaum silaus. L'ombrejat negre indica el màxim fenològic, mentre que el gris indica una proporció més baixa d'individus de la població

\begin{tabular}{lllll}
\hline & Gen Feb Mar Abr Mai Jun Jul Ago Set Oct Nov Des \\
\hline Repòs vegetatiu & & & & \\
\hline Desenvolupament & & & \\
\hline Floració & & & \\
\hline Fruit madur & & & & \\
\hline
\end{tabular}

d'agost a novembre, amb un màxim de fructificació entre setembre i octubre. La planta entra en quiescència entre octubre i novembre. La població de l'obaga de Serra Cavallera, situada més a l'oest, sembla presentar un cicle fenològic més retardat, aproximadament d'uns quinze dies.

\section{Hàbitat}

Pràcticament la totalitat dels exemplars de $S$. silaus de les sis poblacions conegudes actualment a Catalunya apareixen en prats i herbassars higròfils (Fig. 3; vegeu material complementari). Les dades que presentem, però, no incorporen la petita població de la solana de la Serra Cavallera ja que no s'ha pogut caracteritzar per hàbitat. En general, doncs, un $82,18 \%$ dels individus creixen en prats higròfils (Cynosurion cristati); un 9,22\%, en herbassars higròfils de vorada i clariana de bosc (Trifolion medii), i un 5,82\%, en prats de dall (Arrhenatherion elatioris). Una petita part $(1,14 \%)$ apareix en jonqueres (Juncion acutiflorae), i la resta d'exemplars han aparegut en herbassars subnitròfils de l'Aegopodion podagrariae $(1,61 \%)$ de marges de camps i en herbassars nitròfils de vorades i clarianes de bosc del Galio-Alliarion (0,02\%).

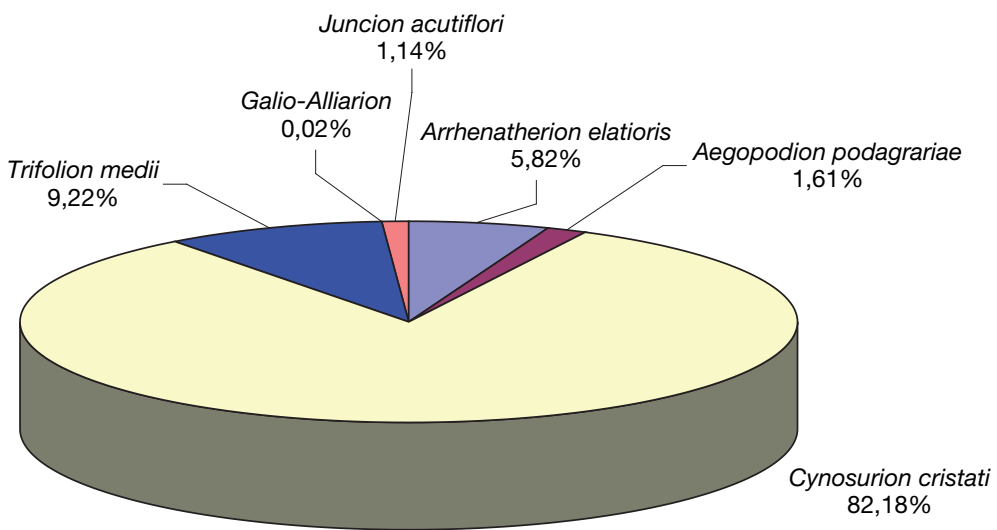

Figura 3. Proporció del grau d'aparició de Silaum silaus en diversos hàbitats. 
La majoria dels exemplars creixen en hàbitats amb baixa intensitat de pastura. En el cas de la localitat de Sant Antoni de Camprodon, S. silaus és abundant de forma general per tota l'àrea de prats que majoritàriament pertanyen a prats ufanosos de l'associació Trifolio-Cynosuretum repentis (inventari 3 del material complementari), i més puntualment a jonqueres del Juncetum acutiflorii (inventari 8 del material complementari), i tots dos hàbitats presenten una pastura poc intensa que comporta una gran riquesa d'espècies i bon estat de conservació de la població. A la resta de localitats només apareix en els marges dels prats de dall (as. RhinanthoTrisetetum flavescentis i Trifolio-Cynosuretum repentis, inventaris 1 i 2, i del 3 al 5 respectivament del material complementari), en les vorades de boscos (AgrimoniTrifolietum medii, inventaris de l'11 al 13 del material complementari), justament on la pressió de la pastura és baixa, o resseguint els marges de cursos d'aigua (Juncion acutiflori, inventaris del 7 al 10 del material complementari).

\section{Densitats per hàbitats}

Igual que en l'apartat anterior, les dades que presentem de densitats per hàbitat no incorporen la petita població de la solana de la Serra Cavallera, ja que no s'ha pogut caracteritzar per hàbitat. Si no considerem els herbassars més ruderals (Aegopodion i Galio-Alliarion), amb menys superfície al territori i menys presència del tàxon, les mitjanes de densitat per hàbitat no són gaire diferents (Fig. 4), una mica més altes als prats del Cynosurion cristati, les jonqueres del Juncion acutiflori i els herbassars de vorada del Trifolion medii (1,54, 1,30 i 1,18 ind./ $\mathrm{m}^{2}$ respectivament), seguits dels prats de dall de l'Arrhenatherion elatioris $\left(0,93\right.$ ind. $\left./ \mathrm{m}^{2}\right)$.

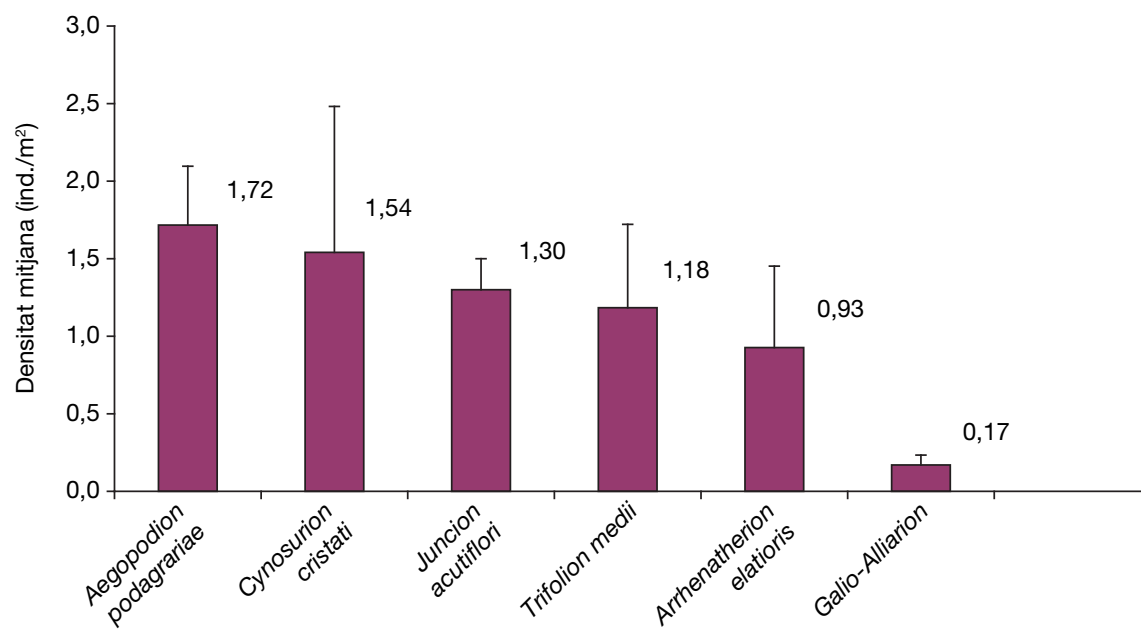

Figura 4. Densitat d'individus per metre quadrat de Silaum silaus en els diversos hàbitats on apareix. Les barres indiquen la desviació estàndard. 


\section{Superfície de presència i d'ocupació}

Segons les dades actuals, a Catalunya $S$. silaus és present en 16 quadrats UTM d' $1 \times 1 \mathrm{~km}(31 \mathrm{~T}$ DG 4284, 4285, 4383, 4384, 4385, 4481, 4483, 4484, 4583, 4584, 4883, 4884, 4984, 4985, 5084 i 5085). La cartografia de la presència de $S$. silaus en les tres primeres poblacions (les situades a Sant Antoni de Camprodon i entorns) ens dóna una superfície de 10,58 ha. En el cas de les poblacions situades a l'obaga de la Serra Cavallera, cal remarcar que S. silaus només és present en una àrea molt petita d'hàbitat idoni, restringida a franges d' 1 a $2 \mathrm{~m}$, als marges de prats i boscos, que significa un $6 \%$ de l'àrea total dels polígons. Per tant, la superfície que ocuparia el tàxon s'estimaria per sota de les 21,38 ha. Finalment, la població de la solana de la Serra Cavallera queda restringida a una petita franja d'1,04 ha als marges d'un curs d'aigua.

\section{Estimació de la població catalana}

El cens directe elaborat en les tres poblacions de Sant Antoni de Camprodon suma 3.891 exemplars reproductors. En l'estimació realitzada per a les dues poblacions de l'obaga de la Serra Cavallera obtenim 5.300 exemplars reproductors, i el cens directe de la població de la solana de la Serra Cavallera suma uns 100 exemplars; per tant, la població global catalana és d'uns 9.300 exemplars reproductors (Taula 1). La població més nombrosa, amb més de la meitat dels efectius (51,66\%), és la de l'obaga de Serra Cavallera (Fig. 5), seguida per la de Sant Antoni de Camprodon (34,26\%), la del Ritortell (6,48\%), la de la riera d'Abella (5,38\%), la del coll de la Creueta $(1,14 \%)$ i la de la solana de Serra Cavallera $(1,08 \%)$.

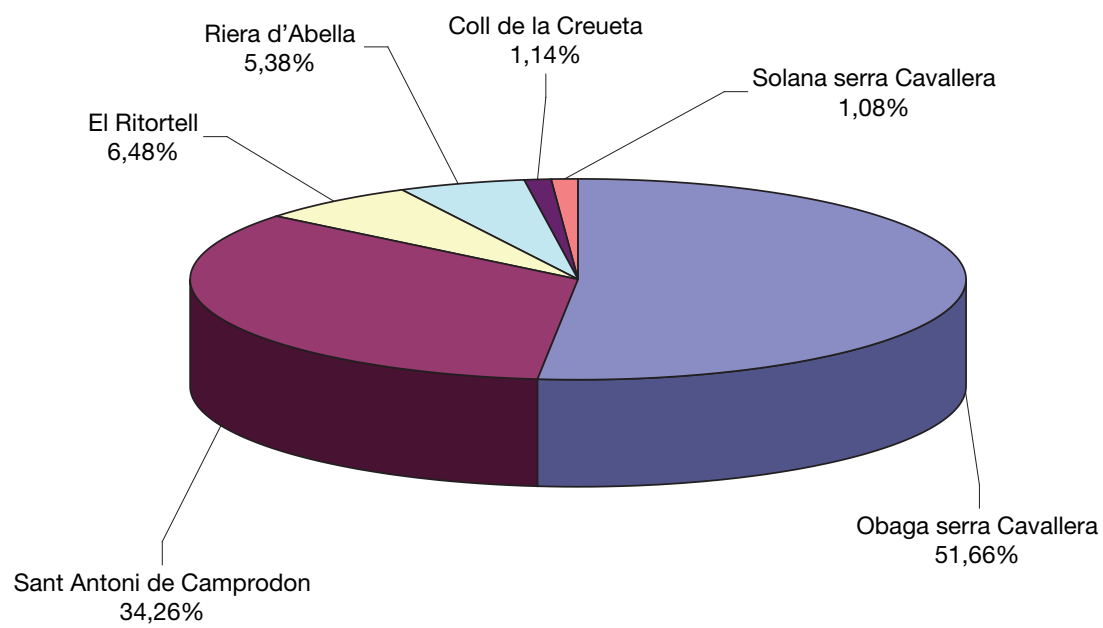

Figura 5. Proporció que representa cada població respecte al total d'individus de Silaum silaus censats a Catalunya. 


\section{Impactes $i$ amenaces}

Tota l'àrea d'ocupació del tàxon presenta uns hàbitats en un fràgil equilibri entre l'abandonament en alguns sectors i la intensificació en d'altres de l'activitat agrícola i ramadera. Més puntualment, també s'han detectat diversos impactes derivats de l'arranjament de vies de comunicació, especialment eixamplament de carreteres i pistes rurals, i també hem detectat algun abocament puntual de runa.

Malgrat la important població de $S$. silaus que s'ha censat, tota ella depèn molt directament de l'activitat ramadera, i podria patir fluctuacions importants en pocs anys. Per exemple, en aquests darrers anys hem detectat una pèrdua d'hàbitat per abandonament de l'activitat agrària al sector de la muntanya de Sant Antoni de Camprodon, on hem trobat individus que creixien ofegats dins dels matolls que han colonitzat zones de pastures. Per contra, especialment a la Serra Cavallera, la planta és molt rara o manca completament en les zones molt pasturades o en prats de dall molt alterats o massa pasturats, i la majoria dels exemplars apareixen en franges estretes als marges de prats de dall, vores de bosc i parcel-les de prats de dall abandonats amb pastura menys intensa.

En un estudi realitzat a Alemanya (Bischoff, 2000) troben que la dispersió de llavors i les taxes de germinació de S. silaus són molt baixes: el 73\% de les llavors d'un individu es dispersen just en un radi d'1,5 m al voltant de l'individu, i només un $1 \%$ de les llavors es troben entre 3,6 i 4,5 m; les taxes de germinació són inferiors al 16\%, malgrat que els individus produeixen un nombre elevat de llavors. Aquestes dades ens fan pensar que la capacitat de colonització de nous sectors al nostre territori ha de ser molt baixa i pot comportar en un futur el declivi d'algunes de les poblacions més degradades per pastura o abandonament. Bischoff (2000) també troba que l'increment de nutrients al sòl degut a la intensificació ramadera causa la desaparició de $S$. silaus. Això ens fa pensar que, malgrat no tenir-ne constància, possiblement $S$. silaus històricament ocuparia més superfície que l'actual i podria ser present on actualment hi ha pastures ruderalitzades, amb una baixa diversitat florística i formades fonamentalment per plantes banals a causa de la forta presència del bestiar, o per la sembra de plantes farratgeres. També la pèrdua de bosquets i línies d'arbres que separaven feixes haurien perjudicat al tàxon, ja que actualment hem trobat que s'hi refugia.

\section{Avaluació de l'estat de conservació}

Sáez et al. (2010) van incloure $S$. silaus en la categoria de vulnerable (VU C1 + 2a(ii); D2), segons criteris UICN (2001). Amb les dades que aportem en aquest article, $S$. silaus mantindria la categoria de vulnerable d'acord amb els criteris $\mathrm{C} 1$, ja que la població estimada no arriba a 10.000 individus reproductors i, a més, es considera que en el sector de Sant Antoni de Camprodon hi hauria hagut una reducció per tancament de pastures de més del 10\% de la població, de l'àrea d'ocupació i de l'hàbitat en els últims deu anys. Bo i això, caldrà fer un seguiment de les actuacions de recuperació d'hàbitat promogudes per la Institució Catalana d'Història Natural amb el suport del propietari del terreny, la Fundació Germans 
Vilariera, l'Ajuntament de Camprodon, la Diputació de Girona i l'obra social de La Caixa realitzades l'any 2010 per veure si es recupera aquesta part de la població perduda. Respecte a l'avaluació realitzada per Sáez et al. (2010), es descartaria el criteri C2a(ii), ja que s'ha passat de conèixer només una subpoblació amb més de 1000 individus reproductors a sis subpoblacions que superen aquesta xifra. Tampoc es pot mantenir el criteri D2, ja que es coneixen més de 5 localitats.

Es podria considerar la presència de poblacions a les comarques septentrionals veïnes un motiu per rebaixar la categoria de risc (UICN, 2003) a NT*, però ho descartem a causa de la baixa capacitat de dispersió de l'espècie, així com pels requeriments de substrat (calcari) i per l'altitud (1000-1420 m) de les poblacions ripolleses, que comporten un fort aïllament respecte a les poblacions nord-catalanes.

\section{Propostes de gestió}

En tota l'àrea de distribució de l'espècie és necessari assegurar una gestió idònia amb l'objectiu de mantenir i no degradar les poblacions de S. silaus. Per una banda, caldria establir una pressió de pastura equilibrada, ja que aquesta afavoreix la presència de l'espècie, però si és excessiva és perjudicial. També caldria conservar i ampliar els espais marginals de vorades de bosc als talussos de les feixes, els marges arbrats i els marges no dallats a les vores dels prats de dall, així com els prats de dall amb feixes estretes en pendents més acusats entre bosquets, ja que són els hàbitats amb més presència i densitat del tàxon protegit. De manera general, s'haurien de potenciar els prats de dall naturals. Per altra banda, caldria posar una especial atenció al tractament de les carreteres i de les pistes que creuen la zona amb presència de $S$. silaus, per evitar impactes com la destrucció d'exemplars i de l'hàbitat, abocament de runa en les vies, especialment al sector de Serra Cavallera, on una part important de la població apareix en aquests ambients i s'han detectat afectacions amb els arranjaments de vials. Per tant, es fa indispensable pactar amb propietaris i masovers una gestió adequada dels hàbitats facilitant produccions més intensives en altres sectors on no apareix $S$. silaus.

Finalment, resulta imprescindible el seguiment a llarg termini de parcel·les distribuïdes en diferents comunitats vegetals on apareix $S$. silaus, ja que pot oferir una informació molt important de com evoluciona la planta i si la gestió que se'n fa és l'adequada o cal readaptar-la. Aquest seguiment ja s'aplica a la població de Sant Antoni de Camprodon, amb la finalitat d'avaluar les actuacions de conservació executades per la delegació de la Garrotxa de la Institució Catalana d'Història Natural a l'any 2010, i també per detectar si la gestió pactada amb els propietaris i el masover es desenvolupa bé i és la idònia per a la conservació del tàxon.

\section{Referències bibliogràfiques}

Bolòs, A. 1949. Anotacions a la Flora Olotina, II. Butll. Inst. Catalana Hist. Nat. 37: 8-16. Bolòs, O.; Font, X.; Vigo, J. (Eds.). 1999. Atlas Corològic, 9; ORCA. IEC (Secció de Ciències Biològiques). Barcelona. 
Bolòs, O.; Vigo, J. 1990. Flora dels Països Catalans. Vol. II. Ed. Barcelona: Barcino.

Bolòs, O.; Vigo, J.; Masalles, R.M.; Ninot, J.M. 2005. Flora manual dels Països Catalans. Barcelona: Ed. Pòrtic.

Bubb, P.J.; Butchart, S.H.M.; Collen, B.; Dublin, H.; Kapos, V.; Pollock, C.; Stuart, S. N.; Vié, J-C. 2009. IUCN Red List Index - Guidance for National and Regional Use. Gland, Switzerland: IUCN.

Cadevall, J. 1913-1937. Flora de Catalunya. Institut d'Estudis Catalans. Barcelona.

eFloras. 2013. Published on the Internet http://www.efloras.org [consultat gener de 2013]. Missouri Botanical Garden, St. Louis, MO \& Harvard University Herbaria, Cambridge, MA.

Fröberg, L. 2009. Silaum L. -In: Flora Nordica electronic version. http://www.floranordica. org/Review/-Review_public/accounts/Silaum.html [consultat gener de 2013].

Generalitat de Catalunya, 2008. Decret 172/2008, de 26 d'agost, de creació del Catàleg de flora amenaçada de Catalunya, Diari Oficial de la Generalitat de Catalunya, 5204, 28 d'agost de 2008 .

Gómez, D. 2003. Silaum Mill. In: Nieto, F.; Jury, S.; Herrera, A. (Eds.). Flora iberica. Vol. X (Araliaceae-Umbelliferae): 236-237. Real Jardín Botánico-CSIC. Madrid.

Gómiz, F. 2003. Silaum silaus (L.) Schinz \& Thell. (Umbelliferae), en la provincia de León. Anales J. Bot. Madrid 60: 228.

Iriondo, J.M. (Coord.). 2011. Atlas y Libro Rojo de la Flora Vascular Amenazada de España. Manual de metodología del trabajo corológico y demográfico. Dirección General de Conservación de la Naturaleza y Sociedad Española de Biología de la Conservación de Plantas. Madrid.

Oliver, X. 2008. Aportacions al coneixement de la flora amenaçada de la Garrotxa. Annals de la Delegació de la Garrotxa de la Institució Catalana d'Història Natural, 3: 29-38.

Oliver, X. 2012. La llista vermella de flora vascular de la Garrotxa, 2009. Ann. Delegació Garrotxa Inst. Catalana Hist. Nat. 5: 29-38.

Sáez, L.; Aymerich, P.; Blanché, C. 2010. Llibre vermell de les plantes vasculars endèmiques i amenaçades de Catalunya. Argania editio. Barcelona.

SILENE. Système d'Information et de Localisation des Espèces Natives et Envahissantes. Conservatoire Botanique National Méditerranéen de Porquerolles 2011. http://flore. silene.eu/index.php [consultat gener de 2013].

UICN 2001. Categorías y criterios de la lista roja de la UICN. Versión 3.1. Comisión de Supervivencia de Especies de la UICN. Gland, Suïssa i Cambridge, UICN.

UICN 2003. Directrices para emplear los criterios de la Lista Roja de la UICN a nivel nacional y regional. Version 3.0. Comisión de Supervivencia de Especies de la IUCN. UICN. 26 pp. Gland, Suïssa i Cambridge, Regne Unit. 


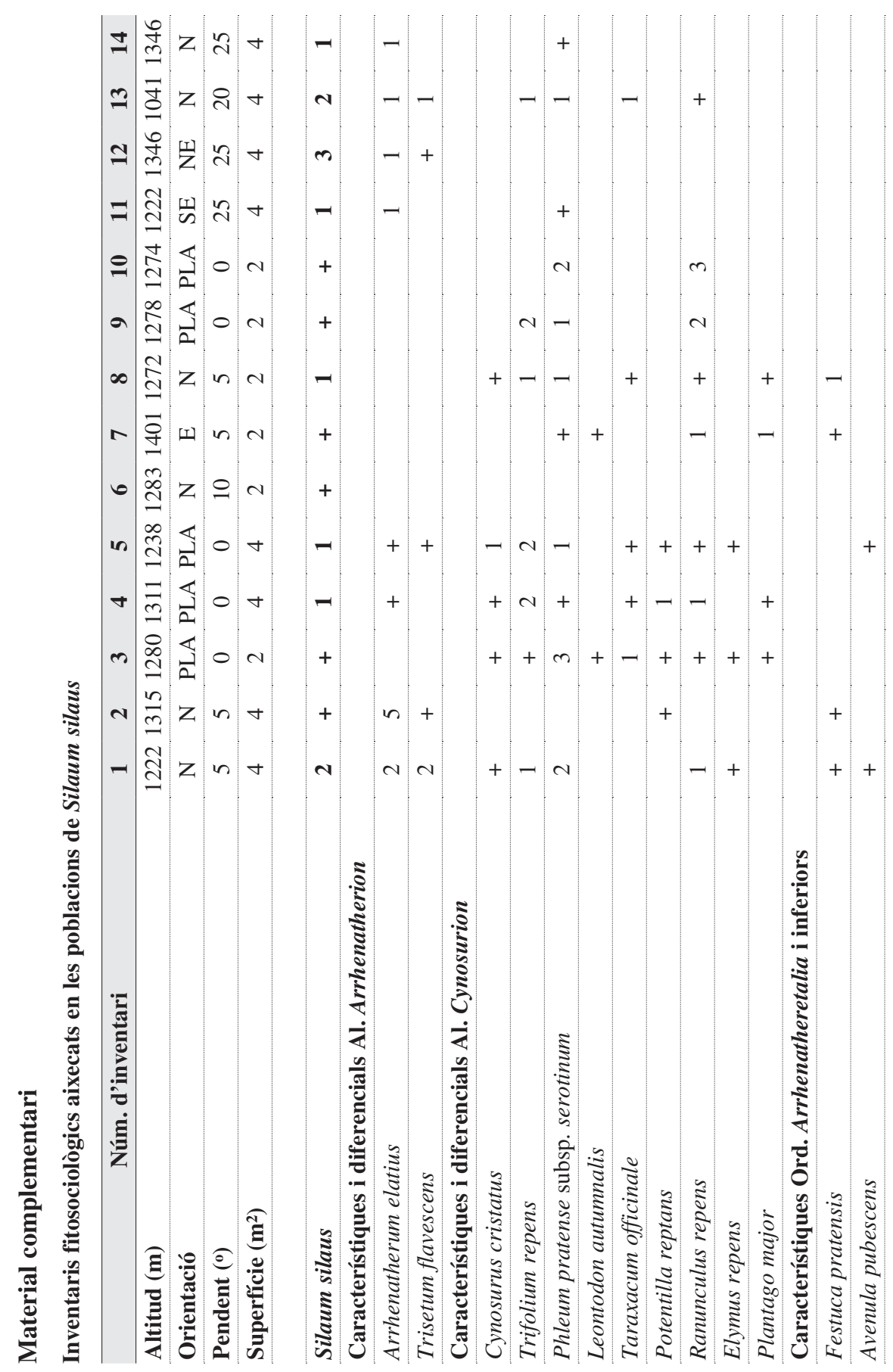




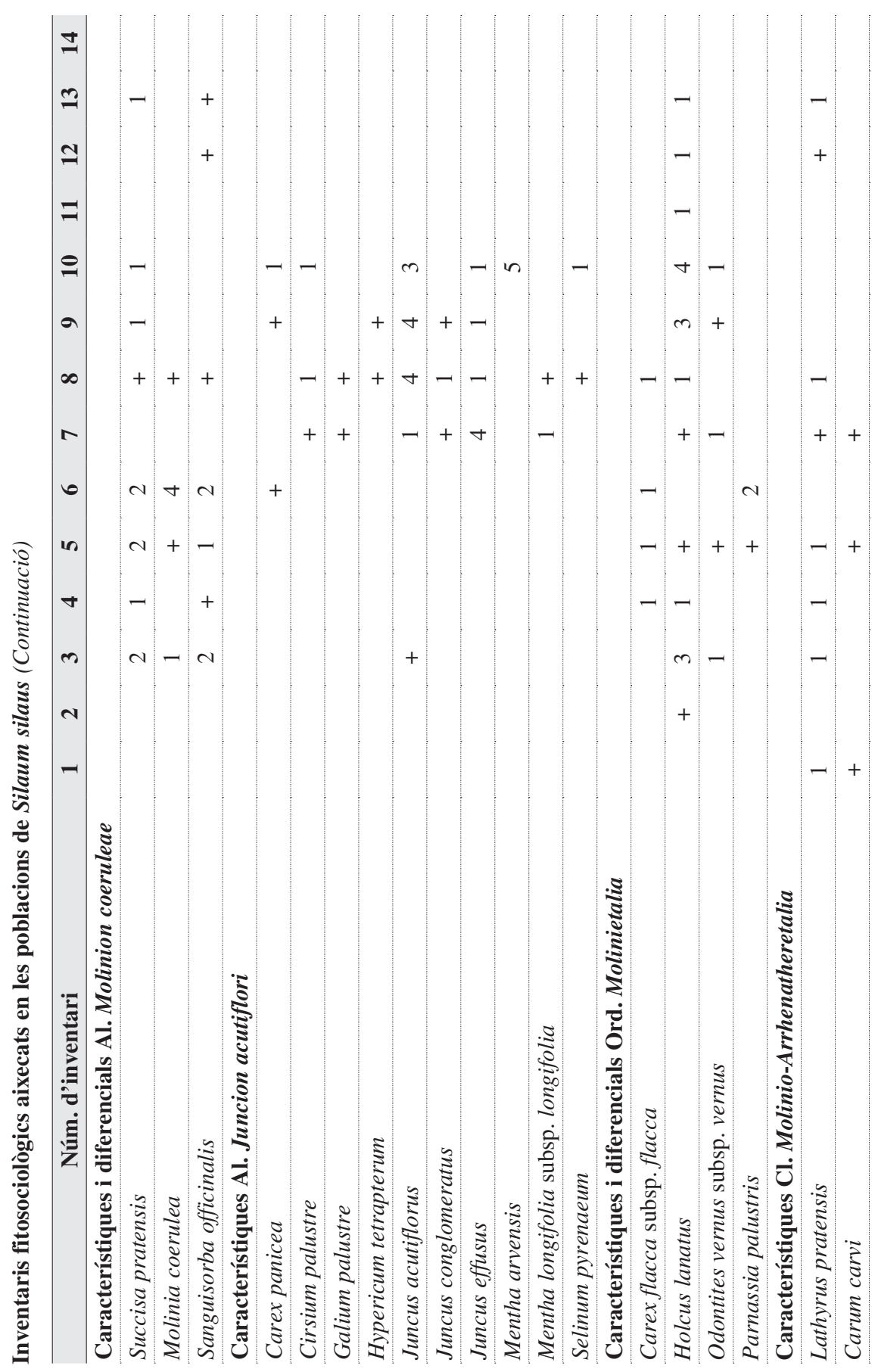




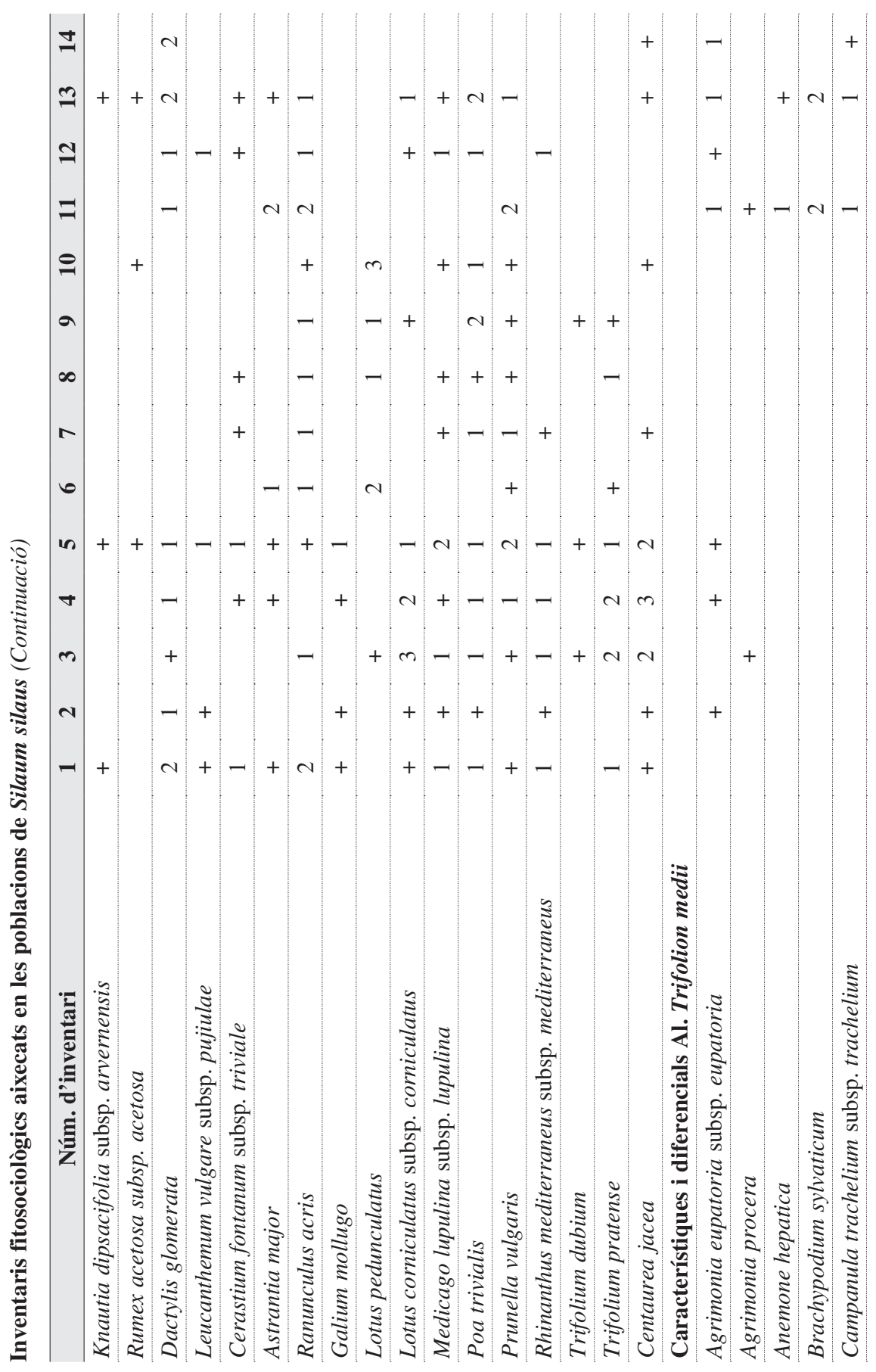




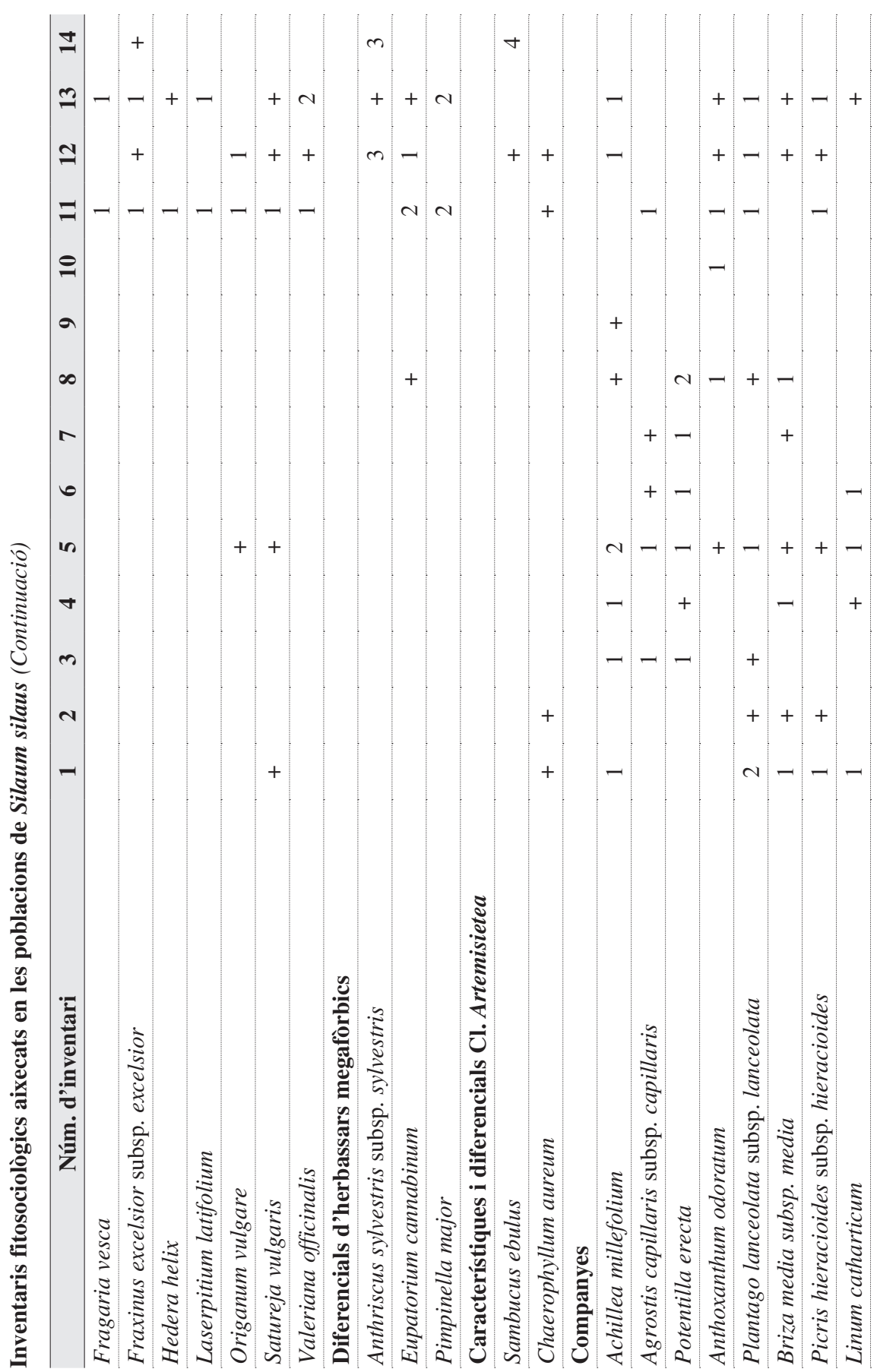




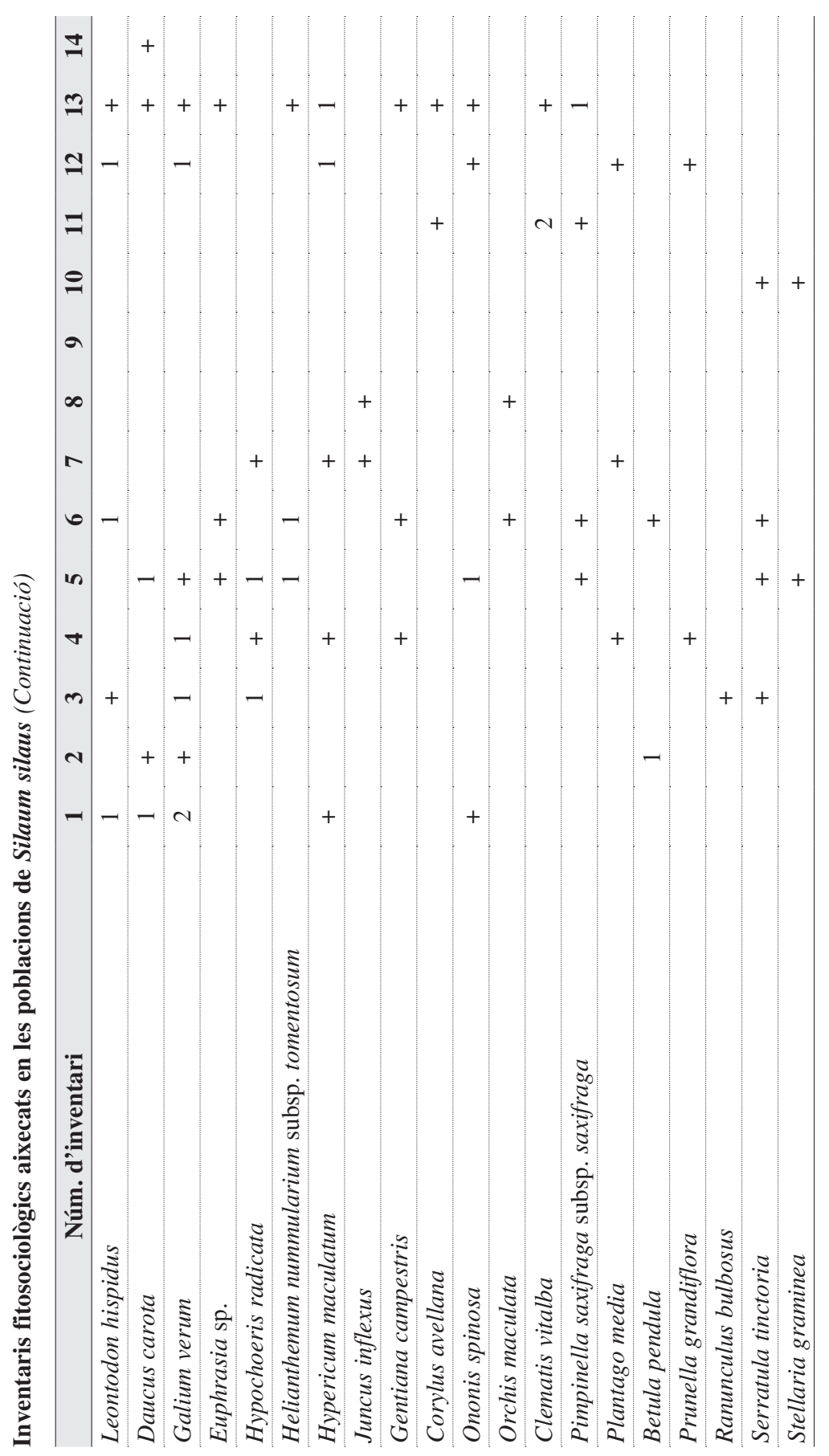




\section{Espècies presents en un inventari}

1: Cirsium arvense (+), Onobrychis viciifolia (+), Centaurea nigra (+); 2: Gentiana cruciata $(+)$, Gentiana verna (2); 3: Trifolium ochroleucon (+); 5: Epipactis palustris (1), Plantago maritima subsp. serpentina (1); 6: Epilobium palustris (1), Alchemilla xanthochlora (1), Polygonum bistorta subsp. bistorta (+); 7: Carex ovalis (1), Typha angustifolia (+), Filipendula vulgaris (1); 8: Agrostis stolonifera (1); 9: Polygonum hydropiper (1); 10: Bromus ramosus subsp. ramosus (1), Aconitum vulparia (1), Chaerophyllum temulentum (+), Populus tremula (+), Salvia glutinosa (+), Stachys sylvatica (+); 11: Eryngium bourgatiii (+); 12: Rubus sp. (+); 14: Dipsacus fullonum subsp. fullonum (+), Galeopsis tetrahit (1), Knautia dipsacifolia subsp. catalaunica $(+)$, Silene vulgaris $(+)$.

Procedència dels inventaris:

Prats de dall (Rhinantho-Trisetetum):

1. Població 5: La Bona Font, Espinalba, Llanars, Ripollès, DG4468, calcosquists, 27-IX-2011.

2. Població 5: Pla del Sastre, Llanars, Ripollès, DG4468, calcosquists, 27-IX2011.

Prats higròfils (Cynosuro-Trifolietum):

3. Població 2: Pla de Bonaire, Sant Antoni de Camprodon, Camprodon, Ripollès, DG4468, sedimentàries acidificades, 5-VII-2005.

4. Població 5: Pla del Sastre, sobre el torrent de la font del Vern, Llanars, Ripollès, DG4468, sedimentàries acidificades, 23-IX-2011.

5. Població 5: Cortal d'Avall, Les Enderrocades, Llanars, Ripollès, DG4468, sedimentàries acidificades, 23-IX-2011.

Prat higròfil (Epipactidi-Molinietum):

6. Població 2: Pla de Bonaire, Sant Antoni de Camprodon, Camprodon, Ripollès, DG4468 sedimentàries acidificades, 15-IX-2005.

Jonquera acidòfila (Juncetum acutiflori):

7. Població 5: Font de les Dous, El Pla Rodó, Vilallonga del Ter, Ripollès, DG4468, calcosquists, 20-VII-2011.

8. Població 2: Pla de Bonaire, Sant Antoni de Camprodon, Camprodon, Ripollès, DG4468, sedimentàries acidificades, 1-VII-2005.

9. Població 2: Pla de Bonaire, Sant Antoni de Camprodon, Camprodon, Ripollès, DG4468, sedimentàries acidificades, 5-VII-2005.

10. Població 2: Pla de Bonaire, Sant Antoni de Camprodon, Camprodon, Ripollès, DG4468, sedimentàries acidificades, 5-VII-2005.

Vorada higròfila (Agrimonio-Trifolietum):

11. Població 5: Les Enderrocades, Torrent del Sordiàs, Llanars, Ripollès, DG4468, calcosquists, 6-X-2011. 
12. Població 5: Font del Vern, Vilallonga del Ter, Ripollès, DG4468, calcosquists, 20-VII-2011.

13. Població 3: Font del Boix, Sant Antoni de Camprodon, Camprodon, Ripollès, DG4468, sedimentàries acidificades, 15-IX-2005.

Herbassars ruderals higròfils (Urtico-Sambucetum):

14. Població 5: Font del Vern, Vilallonga del Ter, Ripollès, DG4468, calcosquists, 20-VII-2011. 
